\title{
Prunella vulgaris L. Potentiates Answer to the Emergence of Dreaded Antibiotic Resistance
}

\author{
Jitendra K. Patel ${ }^{1}$, Chetan Kumar Joshi ${ }^{3}$ and Mukesh Kumar Sharma ${ }^{1,2 *}$ (D) \\ ${ }^{1}$ Department of Biotechnology, Maharaj Vinayak Global University, Jaipur - 302 001, Rajasthan, India. \\ ${ }^{2}$ Department of Botany, Vishwa Bharti PG College, Sikar - 332 001, Rajasthan, India. \\ ${ }^{3}$ Department of Zoology, Government Science College, Sikar - 332 001, Rajasthan, India.
}

\begin{abstract}
Medicinal herbs that are in use for centuries to treat infections and other illnesses. Prunella vulgaris L. is traditionally used for its therapeutic attributes for the alleviation of various infectious diseases. The objective of this study on Prunella vulgaris was to reveal relevant pharmaceutical information to understand its beneficial medicinal uses for human beings. The methanolic and petroleum ether extracts after removal of the solvent under reduced pressure from the Prunella vulgaris plants were prepared and these extracts were analyzed in vitro for their activity against B. subtilis, E. coli, S. aureus and S. typhi (with ATCC numbers 6051, 25922, 23235 and 14028 respectively). Likewise, in vivo studies were conducted using the $E$. coli-induced peritonitis in laboratory rat models where the rats were given allopathic antibiotic ofloxacin and the results were compared with those rats who received plant extracts under controlled conditions. The results were analyzed for the efficacy of the plant extracts was compared with ofloxacin; the methanol extracts exhibited equally if not better results in clearing the pathogen from the system of animals. The petroleum ether extracts exhibited the least antimicrobial activity in comparison to those extracted in methanol isolates. In conclusion, the herbal extract demonstrated significant antibacterial activity both under in-vitro and in-vivo studies which is a major outcome of the study. During this study, all standards and norms were followed as per government animal authority.
\end{abstract}

Keyword: Prunella vulgaris, methanolic extracts, pathogenic microorganisms

\begin{abstract}
*Correspondence: mukeshsharma.dt@gmail.com
(Received: February 04, 2021; accepted: July 22, 2021)

Citation: Patel JK, Joshi CK, Sharma MK. Prunella vulgaris L. Potentiates Answer to the Emergence of Dreaded Antibiotic Resistance. J Pure Appl Microbiol. 2021;15(3):1429-1441. doi: 10.22207/JPAM.15.3.35

(C) The Author(s) 2021. Open Access. This article is distributed under the terms of the Creative Commons Attribution 4.0 International License which permits unrestricted use, sharing, distribution, and reproduction in any medium, provided you give appropriate credit to the original author(s) and the source, provide a link to the Creative Commons license, and indicate if changes were made.
\end{abstract}




\section{INTRODUCTION}

Plants are an incredible source of therapeutic agents since time immemorial and their medicinal efficacies are still being investigated globally. Secondary metabolites help plants and microbes in resisting the onslaught of abiotic and biotic stresses by the changing environmental and growth conditions and it are under these constraints that the organisms start synthesizing secondary metabolites that act as adaptive molecules. As many as two and a half million such secondary metabolites are reported in the literature and the great majority of them are known to possess bioactivity. These bioactive compounds play important roles in imparting defense mechanisms against pest attacks also. Their most important bioactivity is that these compounds can be used as potent herbal drugs and have been isolated and evaluated for their efficacy. Not many of them are commercialized yet as a purified molecule to be used as medicine; however, their crude extracts and powder formulation are prescribed in the Indian Ayurveda and Unani systems of medicine. Humanity has long realized their potential as therapeutic agents and the ancient people almost completely relied upon them as medication for various ailments. Micro-organisms are well-known examples of biosynthesizing secondary metabolites. All antibiotics are obtained from the metabolic machinery of microorganisms and all of them are classified as secondary metabolites. But, in addition to microbes, plant extracts are also known to exhibit antibacterial activity.

Members of the family Lamiaceae (Lavender/Mint family) are a rich source of essential oils, and these are known to possess beneficial therapeutic agents. One of its members, Prunella vulgaris $L$. has also been endowed with a treasure of compounds that are exploited as antimicrobial drugs. Therefore, it has been used as a disinfectant for past many decades. Out of these bioactive molecules, few have been tested and sold in the market as crude pharma compounds and used in home-grown enterprises ${ }^{1}$. Researchers got inclined towards remedial plants in the wake of watching increasingly symptoms of engineered drugs contrasted with their advantages ${ }^{2}$. Prunella vulgaris plants are one to two feet high, that grow wild in and around in Chitrakut region of Madhya Pradesh, India, and also in most other regions of India. In the present study, we have collected its natural populations and attempted to evaluate its antimicrobial activity.

$P$. vulgaris, owing to its numerous curative properties and primarily because of its flavonoids and phenolic compounds is also known as self-heal ${ }^{3}$. In the present investigation, the total phenol and flavonoid content of $P$. vulgaris was assessed. In the wake of widespread resistance to antibiotics, the complexity in peritonitis caused by $E$. coli limits the peritoneal function that affects patients adversely ${ }^{4}$. With its almost negligible side effects and broad-spectrumanti-microbial activity, the $P$. vulgaris extracts were also tested against peritonitis in Albino Wistar rats. This examination was also intended to decide the reason behind the seriousness of peritonitis brought about by $E$. coli. In this study all guidelines were followed for animal use and the experiments were performed with the permission from Institutional Animal Ethical Committee (IAEC) of the PBRI, Bhopal.

Structurally, antibiotics fall in the group of secondary metabolites and they come from either bacteria or fungi. Because of their overusage, wrong prescription and incessant mutation among antibiotic-yielding bacteria, most of the pathogenic microbes have developed resistance. Hence, the focus of the scientists has shifted towards searching for new antibiotics. Plants have a huge reservoir of secondary metabolites. Since $P$. vulgaris is rich in essential and aromatic oils, therefore, to evaluate its antimicrobial efficacy, these experiments were conducted.

\section{MATERIALS AND METHOD}

\section{Selection and collection of plant material}

An exhaustive literature survey is required in the plant selection for such studies, especially for its specific biological efficacy. In this study, Prunella vulgaris $L$. and its parts were selected based on an ethno botanical survey. Natural populations of the plant were collected from the wild and the herbarium of the plant species was prepared and deposited to the Department of Botany, Safia College of Science, Bhopal [Madhya Pradesh, India], for identification and authentication. Plants were authenticated by the 
Head of the Botany department. The herbarium specimen had authentication voucher numbers 140/Bot/Safia/19 and 139/Bot/Safia/19 for Prunella vulgaris is preserved.

It is not without reason that $P$. vulgaris is regarded as self-heal, it synthesizes secondary metabolites that have tremendous potentialities to be exploited to alleviate various ailments in human beings.

Consequently, the entire investigation was divided into two sections. The in vitro investigation included the antimicrobial actions of the extracts against standard bacterial strains obtained from American Type Culture Collection (ATCC), USA. The in vivo studies were based on three parameters i.e., E. coli-induced peritonitis, neutrophils function test, and the survival studies. Furthermore, the phenolic and flavonoids content of the extracts was assessed using standard laboratory protocols.

\section{Processing and preparation of plant extract Solvents}

To prepare extracts of the shade-dried leaves of the $P$. vulgaris, with analytical grade methanol $99.8 \%$ purchased from Sigma-Aldrich; and petroleum ether was obtained from Merck was used.

\section{Maceration}

The shade-dried plant material was broken down into very small pieces in such a way that minimum damage was done to the cells to preserve the essential oils in them. Maceration is a well-tested technique to reduce the plant material intended to be used in the isolation of active compounds. It involves putting the plant material and the organic solvent into contact with occasional shaking in an air-tight container overnight $^{5}$.

Shade dried and macerated $P$. vulgaris $(1 \mathrm{~kg}$ ) powder was transferred to $250 \mathrm{ml}$ conical flasks and methanol was added and kept for 72 hours at room temperature and was shaken at regular intervals. The resultant crude extract was filtered first using a muslin cloth and then after by Whatman filter paper (No. 1). After filtration, the solvent was removed under reduced pressure. The solvent-free dried extract was designated as PVME and was weighed and kept inside the airtight desiccators for further use ${ }^{5}$.

\section{Photochemical Analysis}

Spectrophotometric Quantification of Whole Phenol Content Procedure

Total amount of phenolics present in the extracts was estimated using Folin and Ciocalteu's reagent. Then, Gallic acid was used to prepare the standard curve, and the total phenolics were expressed in terms of Gallic Acid Equivalent (GAE, $\mathrm{mg} / \mathrm{g}$ ). Gallic acid measuring 0.01 to $0.05 \mathrm{mg} / \mathrm{ml}$ was dissolved in methanol to prepare the standard curve. The plant extracts were diluted (10-1) using methanol and $0.5 \mathrm{ml}$ of each of these samples were taken in a test tube, to which $2.5 \mathrm{ml}$ of diluted (10-fold) Folin and Ciocalteu's reagent and finally $7.5 \%$ sodium carbonate $(2 \mathrm{ml})$ were added. These test tubes were then covered with para film and were incubated for $30 \mathrm{~min}$. at ambient room temperature $\left(15-25^{\circ} \mathrm{C}\right)$. After $30 \mathrm{~min}$. the absorbance in each test tube was measured at 760 $\mathrm{nm}$ via spectrophotometer. All of these operations were performed in technical triplicates. The Folin and Ciocalteu's reagent is reactive to polyphenols and upon reaction, it generates a blue color that was measured spectrophotometrically ${ }^{6}$.

A Gallic acid standard curve was used as a reference for the evaluation of unknown total phenolics content in the $P$. vulgaris extracts. Line of regression from gallic acid was used for estimation of unknown phenolic content in our sample. From this curve of gallic acid, the regression line was estimated to be:

$$
y=0.002 x+0.063 \text { and } R 2=0.995 ; \text { (where }
$$

$y$ is the absorbance)

\section{Spectrophotometric Quantification of Total Flavonoid Content \\ Methodology}

Colorimetric assay described by Dewanto et $\mathrm{al}^{20}$ was employed to find out the total flavonoids present in the plant extracts. The diluted sample of extracts and the standard solution of quercet in were added into a $75 \mu \mathrm{l}$ of sodium nitrite solution, and it was mixed continuously for $6 \mathrm{~min}$. To this mixture, $0.15 \mathrm{ml}$ of aluminum chloride solution $(100 \mathrm{~g} / \mathrm{L})$ was added; and after $5 \mathrm{~min} ., 0.5 \mathrm{ml}$ of sodium hydroxide was added to this mixture. Using distilled water; the volume was finally made up to $2.5 \mathrm{ml}$. and mixed thoroughly. Then, the absorbance of this mixture was measured at 510 
$\mathrm{nm}$. This mixture without the extract was taken as blank. The total content of flavonoid was expressed in terms of $\mathrm{mg}$ quercetin/g dry weight (mg/g DW), using Querctin's calibration curve prepared earlier. This experiment was conducted in triplicates. The regression line drawn for quercetin was used to estimate flavonoid (unknown) content in the extracts. From quercetin's standard curve, a regression line was found as: $Y=0.001 x+0.120$ and $r 2=0.988$.

Thus, by putting the value of the absorbance of the tested sample ( $\mathrm{Y}=$ absorbance) the goodness of fit was calculated ${ }^{7}$.

\section{Whole Flavonoid Contents (TFC)}

\section{In-Vivo Antibacterial Study}

Peritonitis is an inflammation of the inner lining of our body. It is a silk-like membrane that encloses the internal organs also, and the inflammation of this membrane is caused by a bacterial or fungal infection. Infection or no infection, peritonitis causes systemic inflammation because it damages the peritoneal layer which often leads to mortality. In the present study, the peritonitis was induced by injecting $E$. coli (ATCC 25922) in the Albino Wistar rats and the antibacterial activity of the extracts was studied in vivo ${ }^{7}$.

Parameters included in E. coli-induced peritonitis in the in vivo antibacterial study

- E. coli-in the Albino Wistar rats.

- Neutrophils Function Test

- Survival Study

Characteristics of the animals used

Albino Wistar rats were employed in the study were procured from the Pinnacle Biomedical Research Institute (PBRI), Bhopal, India. All the animal experiments were approved and cleared by the Institutional Animal Ethical Committee (IAEC) of the PBRI, Bhopal bearing.

Table 1. Treatment groups for in vivo antibacterial study

\begin{tabular}{lll}
$\begin{array}{l}\text { Group } \\
\text { No. }\end{array}$ & Treatment & $\begin{array}{l}\text { Noofanimals } \\
\text { per group }\end{array}$ \\
\hline I & Vehicle & Six \\
II & Ofloxacin $(10 \mathrm{mg} / \mathrm{kg} \mathrm{b} / \mathrm{w})$ & Six \\
III & PVME $(100 \mathrm{mg} / \mathrm{kg} \mathrm{b} / \mathrm{w})$ & Six \\
\hline
\end{tabular}

The committee for Control and Supervision of Experiments on Animals (CPCSEA) registration no. - 1824/PO/ere/s/15/CPCSEA. The convention reference number is pbri/iaec/pn. Following were the features of the animals used in the study:

$\begin{array}{ll}\text { Strain - } & \text { Albino Wistar } \\ \text { Age } & 13-14 \text { weeks } \\ \text { Sex - } & \text { either sex } \\ \text { Bodyweight - } & 200 \pm 20 \mathrm{~g} \\ \text { Route of administration- } & \text { P.O }\end{array}$

\section{Groups for $E$. coli-induced peritonitis}

The animals were divided into three groups. Details of the treatment are being given below:

Group-I: Animals acted as Control where Normal saline $+E$. coli were injected via I.P.

Group-II: Animals were given ofloxacin $10 \mathrm{mg} / \mathrm{Kg}$ body mass per os (oral administration). $+E$. coli was injected via i.p.

Group-III: Animals were administered with the plant extract at $100 \mathrm{mg} / \mathrm{kg}$ body mass p.o. + E. coli via i.p.

E. coli strain in this study was acquired from the American Type Culture Collection, USA, and maintained on supplement agar in our laboratory, and these cultures were used for all examinations. The $E$. coli (ATCC-25922) lifted from a single and well-isolated colony was cultured on supplement broth and incubated at $37^{\circ} \mathrm{C}$ for $16-18$ hrs. to attain uniform developmental stage. The culture suspension was then spun at (200 rpm) for $10 \mathrm{~min}$. at $4^{\circ} \mathrm{C}$, and the pellet was re-suspended in Phosphate Buffered Saline (PBS), and Optical Density (OD) was taken at $660 \mathrm{~nm}$, a cell density that concorded to approximately $108 \mathrm{CFU} / \mathrm{ml}^{8}$.

\section{Neutrophiles function test}

Neutrophils are the cells that are the type of phagocytes that assist in the innate immune system and together with monocytes are among the first to respond at the site of the injury or infection earliest responders to infection. Neutrophils help in disabling the invading microorganisms by digesting them and thus preventing infection ${ }^{9}$.

After 14 day's treatment, the Differential Leukocyte Count (DLC) was determined (UB) from the blood taken from the retro-orbital plexus of each rat into heparin vials ${ }^{9}$. Once the counting was done, these blood samples along with $80 \mathrm{mg}$ nylon fibers/ml (NFTB) were kept at $37^{\circ} \mathrm{C}$ for 15 
$\min$. After the incubation, the blood samples were analyzed again for differential and total leukocyte counts respectively to arrive at the neutrophil index. The neutrophil adhesion percentage was determined according to the formula given below: Neutrophil adhesion $\%=$ NIu - NIt $\times 100 /$ NIu .

Here, NIt is the neutrophil index of treated blood samples (NFTB) and Nlu is the neutrophil index of untreated blood samples $(\mathrm{UB})^{10}$.

\section{Survival studies}

Animals were orally given the extracts and the standard antibiotics on the zero-day; $1 \times 108$ viable $E$. coli was injected intraperitoneally (i.p.). In the first twenty hours, the survival of the rats was monitored on an hourly basis, and for the remaining period till 14 days, it was monitored daily basis ${ }^{11}$.

Bacterial studies

Blood samples of model rats used in the experiment were taken from their tail vein at the

\section{Total Phenolic Content in two different extract types of P.vulgaris}

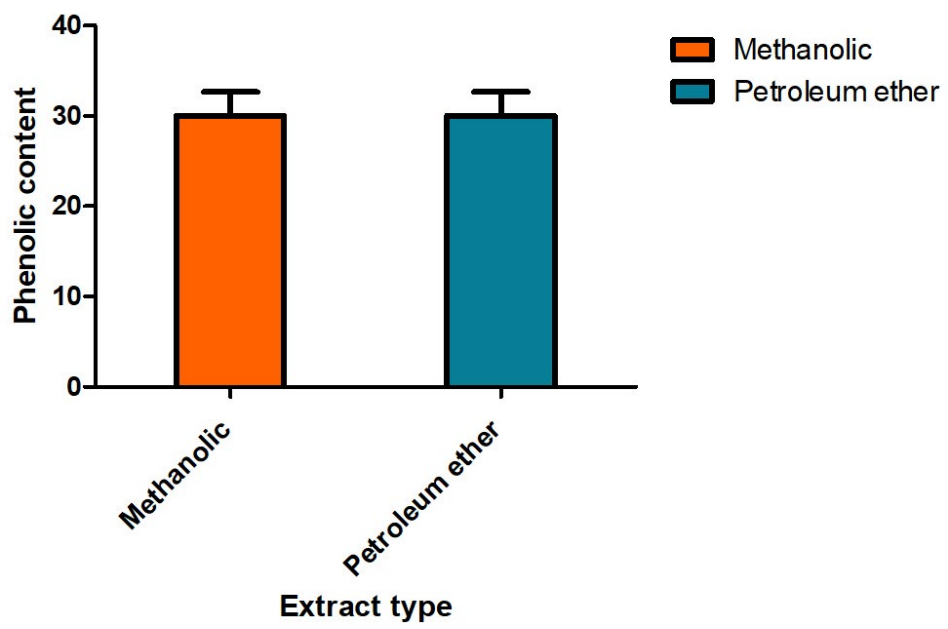

Fig. 1. Total Phenolic Content in methanolic and petroleum ether extract of $P$. vulgaris.

\section{Total Flavonoid Content in two different extract types of P.vulgaris}

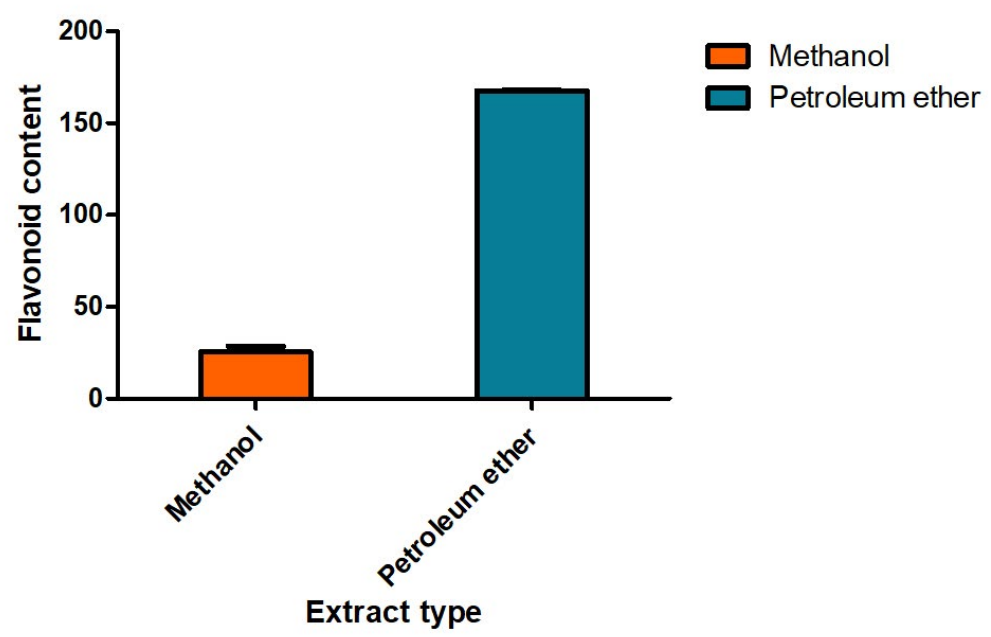

Fig. 2. Total flavonoid content (TFC) in petroleum ether and methanolic extract of $P$. vulgaris (PVME) 
end of the experiment (the time when maximum mortality occurred) was used to determine the presence of $E$. coli in all groups ${ }^{12}$. The blood samples were serially diluted and spread on the nutrient agar in triplicate and the colonies were counted after $24 \mathrm{hrs}$ of incubation at $37^{\circ} \mathrm{C} .{ }^{12}$.

\section{In-Vitro Antibacterial Study}

To find out whether these plant extracts possess any antibacterial activity, different extracts were subjected to the agar well diffusion assay ${ }^{13}$. Following four bacterial strains obtained from American Type Culture Collection (ATCC) were used in the study. E. coli- ATCC- 25922, S. aureusATCC-23235, B. subtilis- ATCC 6051, S. typhi- ATCC14028

\section{Nutrient Agar Medium}

Nutrient agar medium (HiMedia) was prepared by adding $28 \mathrm{~g}$ of dehydrated powder, in one liter of double-distilled water (DDW), and autoclaved; and the molten state of the medium was poured into $90 \mathrm{~mm}$ diameter Petri plates (25$30 \mathrm{ml} /$ plate).

\section{Procedure}

The methanolic extracts of the $P$. vulgaris were diluted and used at the concentration of 25 , 50, 75, and $100 \mathrm{mg} / \mathrm{ml}$. Petri plates containing nutrient agar media were prepared. Microbial suspension of the density of $1 \times 108 \mathrm{CFU} / \mathrm{ml}$ of each of E. coli, S. aureus, B. subtilis, and S. typhi was used for spreading on the Petri plates containing the Nutrient agar media. Then, 4 wells of $5 \mathrm{~mm}$ depth and $6 \mathrm{~mm}$ diameter were made on the semi-solid agar in each Petri plate using a borer. Different concentrations of the plant extracts were prepared, and a positive control consisting of ofloxacin, $10 \mu \mathrm{g} / \mathrm{ml}$, were dispensed (50 $\mu \mathrm{l}$ )

\section{Antibacterial activity of methanolic extract of P.vulgaris}

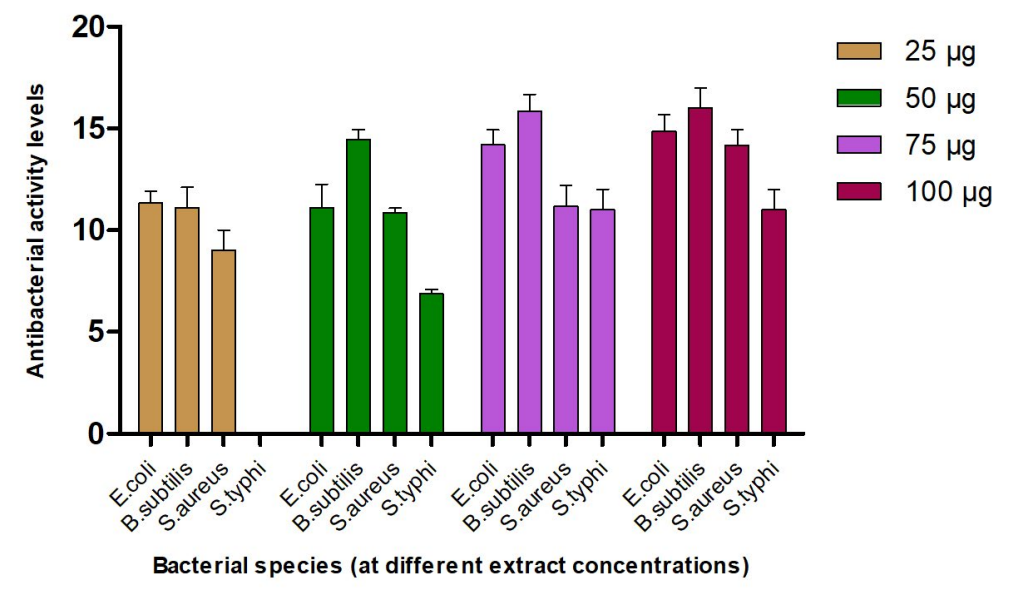

Fig. 3. Antibacterial activity of $P$. vulgaris (methanolic) extract.

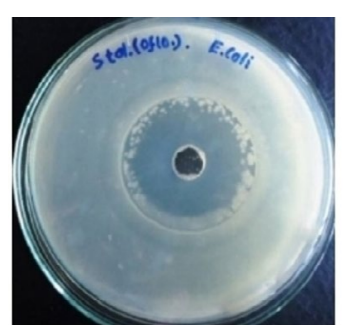

Plate 1

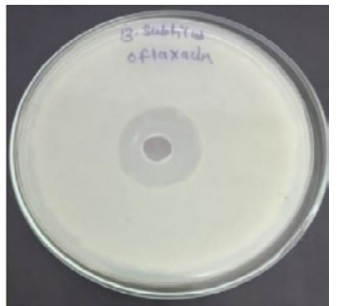

Plate 2

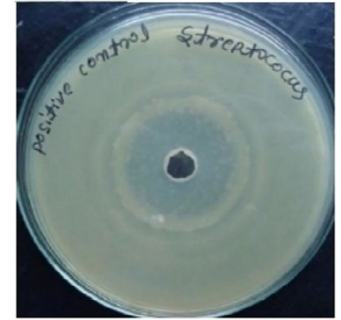

Plate 3

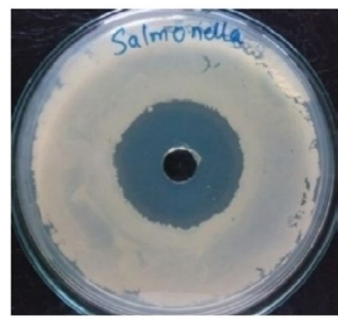

Plate 4

Fig. 4. Plate 1 \& 2. Anti-Bacterial Activity of Ofloxacin against $E$. coli and $B$. subtilis

Fig. 5. Plate $3 \& 4$. Anti-Bacterial Activity of Ofloxacin against $S$. aureus and $S$. typhi. 
in different wells. The inoculated plates were kept at room temperature for $1 \mathrm{hr}$. to allow the diffusion of the extract, and consequently, these plates were incubated for $24 \mathrm{hrs}$ at $30^{\circ} \mathrm{C}$. After incubation, the zones of inhibition around each well were measured with the help of Vernier caliper and the mean values of the diameter of zones of inhibition and the standard deviations were further calculated. All experiments were conducted in triplicates.

\section{Statistical Analysis}

All data was statistically analyzed through SPSS one-way ANOVA.

\section{RESULTS}

To assess its bioactivity, P. vulgaris methanol and petroleum ether extracts were prepared. All the standard tests were done to estimate the total content of phenolic, flavonoids compounds and the results are given in Fig. 1 \& 2 .

To find out the amount present, suitable standard curves were generated and quantities were derived out by comparing them with these curves. Interestingly, the methanol is better organic solvents as compared to petroleum ether while preparing the extracts of the $P$ vulgaris, hence, when total phenolic content in $P$. vulgaris was compared in the two extracts, methanolic extracts showed a better yield of total phenolic content than found in the petroleum ether. Total flavonoids also showed the same trend.

For assessing their antimicrobial efficacy, standard microbiological laboratory methods were employed, and standard growth media and reagents were used. The results of antibacterial action demonstrated by the plant extracts against the four following bacterial strains are given in Fig. 3.

It was found that the methanolic extracts of $P$. vulgaris effectively restricted the growth of E. coli at conc. of $100 \mu \mathrm{g} / \mathrm{ml} \mathrm{Fig.} 6$ (Plate 5 $\& 6)$ while against $B$. subtilis the extracts were effective at a conc. of $50 \mu \mathrm{g} / \mathrm{ml}$. Fig. 7 (Plates $7 \&$ 8). Whereas the extracts against $S$. aureus were able to kill the bacteria at $100 \mu \mathrm{g} / \mathrm{ml}$, Fig. 8 (Plates 9 \& 10), showing lesser bioactivity compared to other mentioned. It was, however, interesting to note that the Salmonella typhi showed complete resistance towards methanolic extracts of $P$ vulgaris Fig. 9 (Plates 11 \& 12).

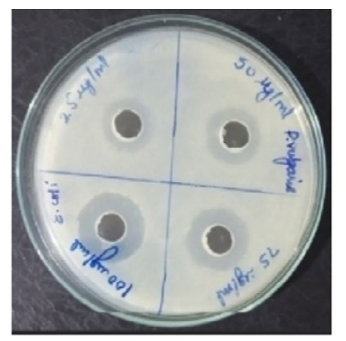

Plate 5

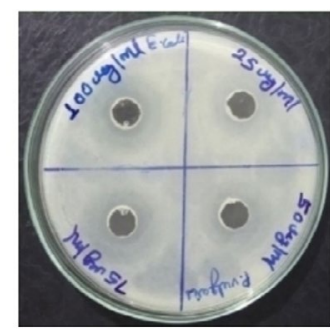

Plate 6

Fig. 6. Plate 5 \&6 Anti-Bacterial Activity of Methanolic Extract of $P$. vulgaris against $E$. coli

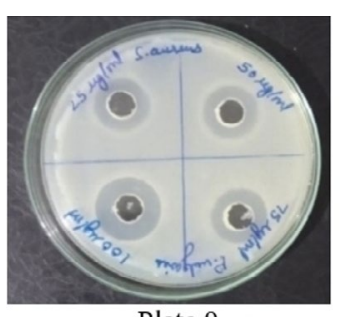

Plate 9

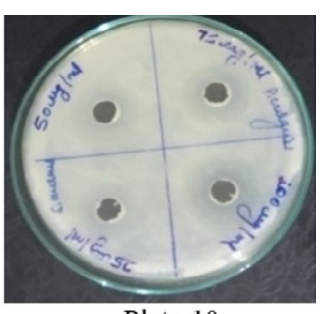

Plate 10

Fig. 8. Plate 9 \& 10 Anti-Bacterial Activity of Methanolic Extract of $P$. vulgaris against $S$. aureus.

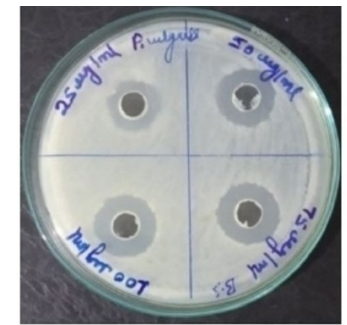

Plate 7

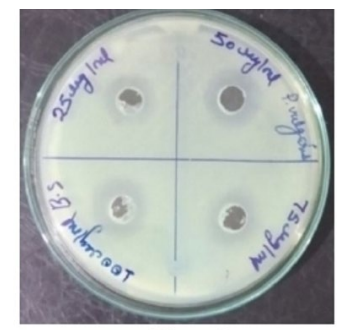

Plate 8

Fig. 7. Plate 7 \& 8. Anti-Bacterial Activity of Methanolic Extract of $P$. vulgaris against $B$. subtilis

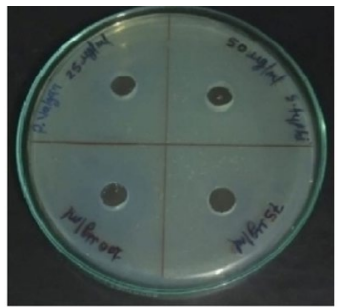

Plate 11

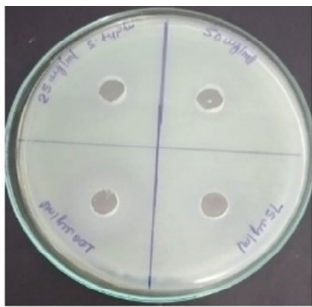

Plate 12
Fig. 9. Plate $11 \& 12$. Anti-Bacterial Activity of Methanolic Extract of $P$. vulgaris against $S$. typhi. 


\section{Anti-Bacterial Activity of Methanolic Extract of P. vulgaris}

Standardantibacterial Agent (Ofloxacin $10 \mu \mathrm{g} / \mathrm{ml}$ )

Name of the Organism $\quad 10 \mu \mathrm{g} / \mathrm{ml}$

E. coli

$22.25 \pm 0.500$

B. subtilis

$30.50 \pm 0.577$

S. aureus

$25.50 \pm 0.577$

S. typhi

$33.50 \pm 0.408$

The antimicrobial ability of the methanolic extracts of $P$. vulgaris was also tested against the two fungal strains. The methanolic extract (ME) of $P$. vulgaris demonstrated significant clearing zones (anti-fungal activity) in the case of $A$. niger but the zones of inhibition were much more pronounced against $C$. albicans where the clearing started appearing at the $25 \mathrm{\mu g} / \mathrm{ml}$ but the maximum zone was observed at the conc. of $100 \mu \mathrm{g} / \mathrm{ml}$ of ME extract of $P$. vulgaris Fig.10-12 (Plates13-16).

\section{In vivo antibacterial study} Animal house condition

Animals in this experiment were selected randomly from the animal house and were segregated into various treatment groups randomly. The animals were maintained in a propylene-coated cage with sterile straw spread on the floor. The relative humidity of about 30.7 $\%$ at $22 \pm 2{ }^{\circ} \mathrm{C}$ and $12 \mathrm{hrs}$ each of light and dark cycles were maintained in the animal house. These animals were fed using the standard pellets (Golden Feeds, New Delhi, India) and water.

The bacterial clearance ability when compared with the allopathic ofloxacin antibiotic and $P$. vulgaris extract, it was revealed that even among Albino Wistar rats the standard ofloxacin is effective at $10 \mathrm{mg} / \mathrm{kg}$ body weight which is an expected result but the PVME also shows

\section{Antifungal activity of methanolic extract of $P$.vulgaris}

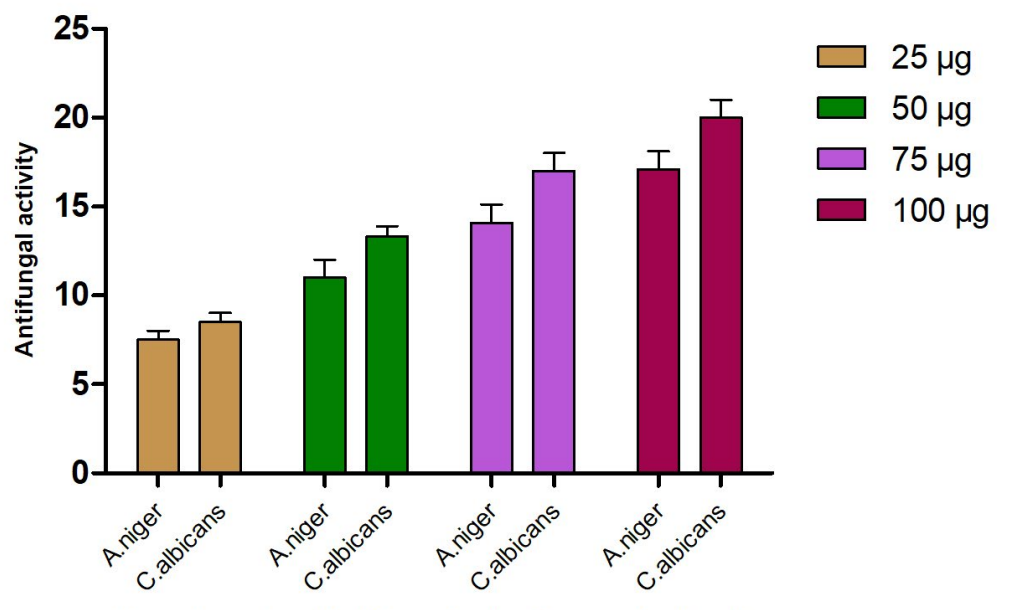

Fig. 10. Anti-fungal activity of methanolic extract of $P$. vulgaris.

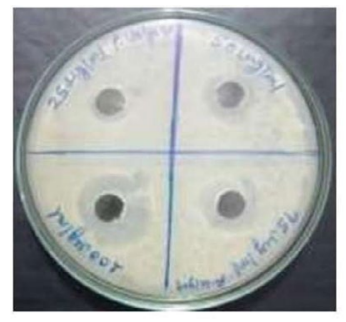

Plate 13

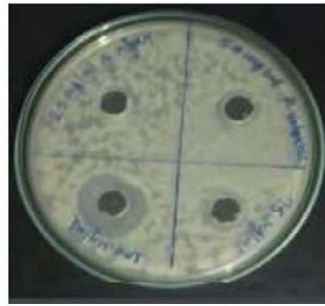

Plate 14

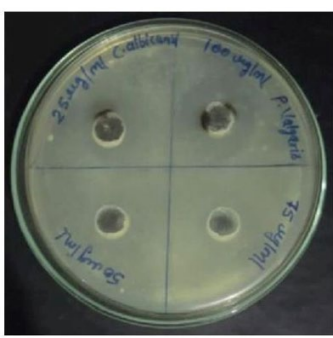

Plate 15

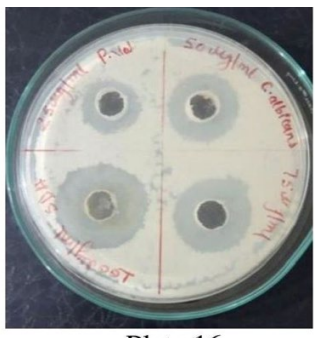

Plate 16

Fig. 11. Plate no. $13 \& 14$. Anti-Bacterial Activity ofMethanolic Extract $P$. vulgaris against $A$. niger.

Fig. 12. Plate 15 \&16. Anti-Bacterial Activity of Methanolic Extract $P$. vulgaris against $C$. albicans. 
clearance activity though at higher concentration i.e., at $100 \mathrm{mg} / \mathrm{kg}$ BW Table 2 \& Fig. 13 (Plates 1719), confirmed significant in vitro results.

\section{In vivo Bacterial Clearance}

E. coli-induced peritonitis, sampling of the tail blood at the end of the experiment (a time when maximum mortality occurs) was used to determine the presence of $E$. coli in all the groups by counting well separated bacterial colonies on the Petri plates. The blood samples thus collected were serially diluted and a measured amount was placed on Petri plates on the nutrient agar in triplicate and Petri plates were incubated at $37^{\circ} \mathrm{C}$; thus produced colonies were then counted after $24 \mathrm{hrs}$. of incubation. The mortality recorded in the sample consisting of PVME at $100 \mathrm{mg} / \mathrm{kg}$ body weight was reduced to $60 \%$ compared to $100 \%$ mortality in control, suggesting that ME of $\mathrm{P}$ vulgaris showed a positive effect in reducing the mortality among $E$. coli induced peritonitis in laboratory-reared rats Fig. 13 (Plates 17, 18 and 19).

Neutrophil Functions (Phagocytic Index) results are provided in Table 3. The neutrophil adhesion percentage was reduced in the sample of $100 \mathrm{mg} / \mathrm{kg}$ which was 5.55 as compared to the control and standard which showed 6.10 and $7.13 \%$ of neutrophile adhesion. Phagocytosis by neutrophils is taken as the main defense system against microbial infections in peritonitis. Phagocytic cells play a significant role in preventing sepsis by eliminating bacteria from the system. Therefore, effective clearing of bacteria is critical for host survival from infection. Here, the effect of ofloxacin at $10 \mathrm{mg} / \mathrm{kg}$ body weight was 6.177 while in the sample of PVME was 4.26. Statistically showing almost similar action but in the case of ofloxacin, expectedly, better results of clearance were observed at much lower concentration compared with the action shown by the MEPV.

Animals pre-handled with extracts and antibiotics on the 0 days, approximately $1 \times 108 E$. coli were injected intraperitoneally (i.p.), and Table 4 shows the results of survival rate after 14 days. Survival Rate (14 Days).

In this parameter, the mortality was observed for 14 days i.e., after the completion of the experiment mentioned in Table 4. A sampling of the tail blood was done at the end of the experiment (the time when maximum mortality occurred), and the appearance of well-separated bacterial colonies on the nutrient agar plates was counted to determine the presence of $E$. coli in all the groups.

In the Control group the number of dead rats was 5 and mortality was found to be $100 \%$; the number of deaths in the group given the standard drug was only one and mortality was calculated to be $20 \%$, but when the survival rate for the animal group treated with the sample polyvinyl methyl ether (PVME) $100 \mathrm{mg} / \mathrm{kg}$ was analyzed, the number of deaths was 3 , and mortality was found to be $60 \%$. These results of in vivo studies carried out with the Albino Wistar rats also further support the findings of the in vitro antimicrobial studies that the PVME is playing a role in eliminating pathogenic microbes from the host system and it

Table 2. Bacterial clearance study

\begin{tabular}{lcc}
\hline CONTROL & $\begin{array}{c}\text { OFLOXACIN } \\
10 \mathrm{mg} / \mathrm{kg} \mathrm{BW}\end{array}$ & $\begin{array}{c}\text { PV ME } \\
100 \mathrm{mg} / \mathrm{kg}\end{array}$ \\
\hline $253.83 \pm 13.378$ & $77.83 \pm 6.177$ & $111.83 \pm 4.262$ \\
\hline
\end{tabular}

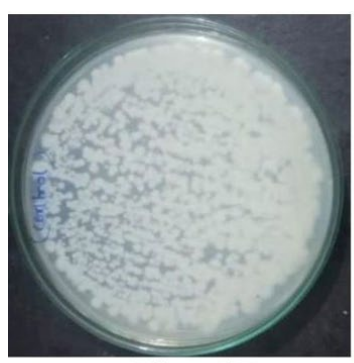

Plate 17

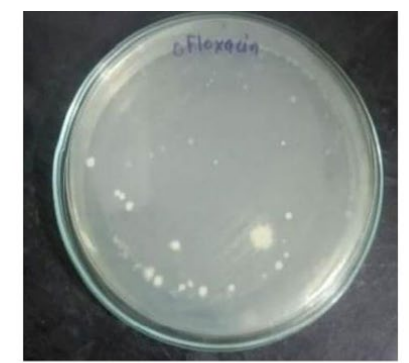

Plate 18

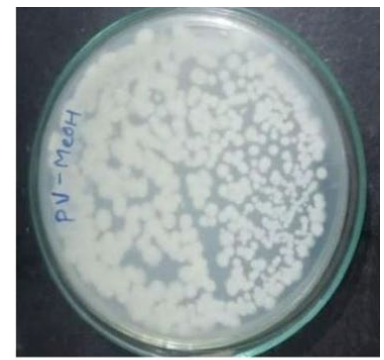

Plate 19

Fig. 13. Plate $17,18 \& 19$. In vivo bacterial clearance Control, Standard and PVME 


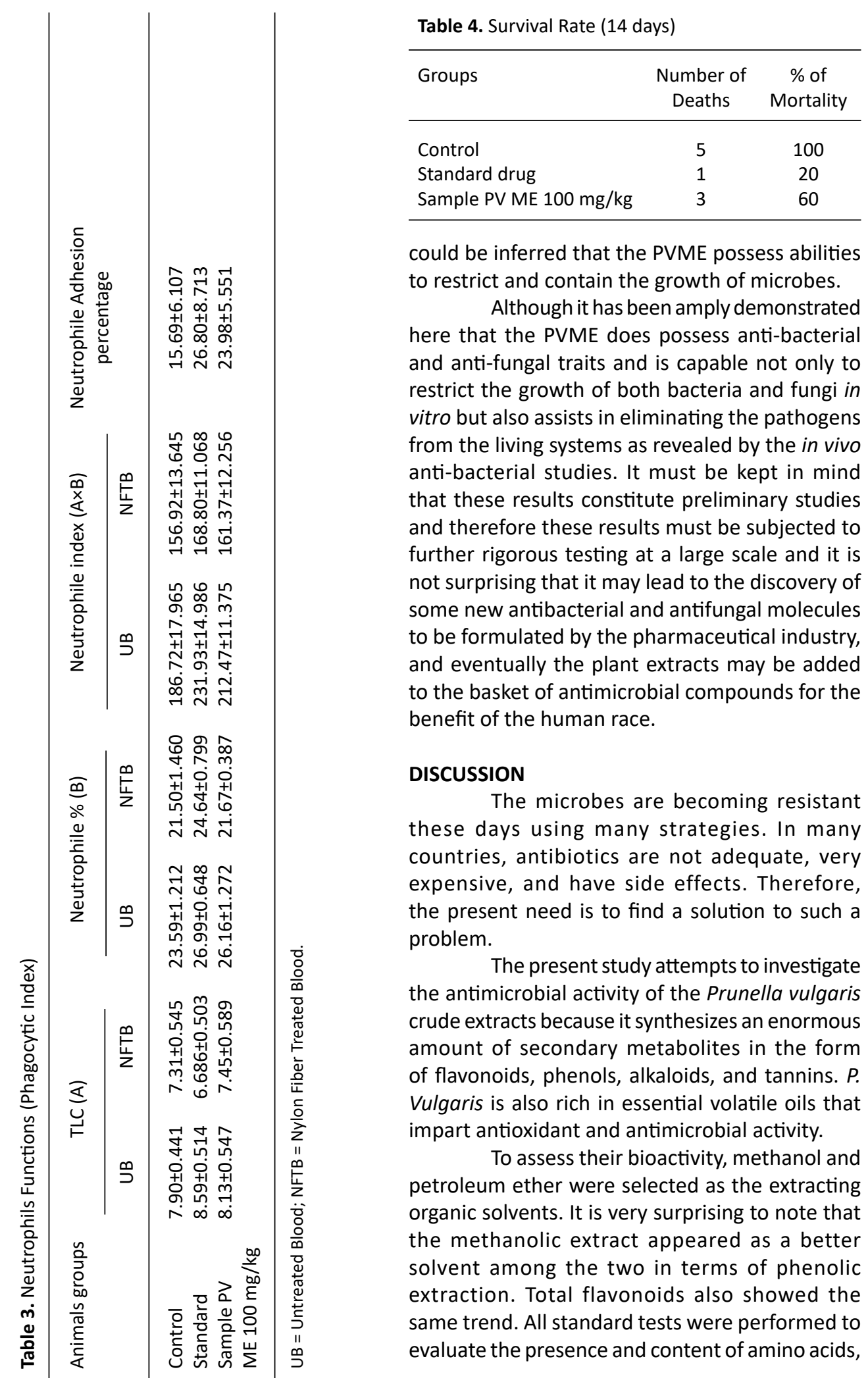


carbohydrates, alkaloids, glycosides, saponins, triterpenoids, flavonoids, sterols, tannins, phenolic compounds, and oil and fats. To find out the amount present, suitable standard curves were generated and quantities were derived out by comparing them with these curves. . In one other study, chloroform extract had the highest phenolic content while flavonoid content was highest in the hydro alcoholic extract ${ }^{19}$.

The antimicrobial activity of the methanolic extracts was also tested against the two fungal strains. The ME of $P$. vulgaris demonstrated significant clearing zones in the case of $A$. niger but the zones of inhibition were much more pronounced against $C$. albicans where the clearing started appearing at the $25 \mu \mathrm{g} / \mathrm{ml}$ but the maximum zone was observed at the conc. of $100 \mu \mathrm{g} / \mathrm{ml}$ of ME extract of $P$. vulgaris Plate 23 26. Similarly, methanol extract had shown better inhibition than ethanol extract. But, A. niger had lower MIC than C.albicans ${ }^{18}$.

In general, out of the two types of extracts, ME was found to impart a higher protective effect as compared to petroleum ether that may be attributed to the higher amounts of phenolics compounds in ME.

Acute oral toxicity study of an extract of methanol of Prunella vulgaris was carried out according to OECD-423 guidelines in mice. Five $\mathrm{mg} / \mathrm{kg}, 50 \mathrm{mg} / \mathrm{kg}, 300 \mathrm{mg} / \mathrm{kg}$ and $2000 \mathrm{mg} /$ $\mathrm{kg}$ were used as dose range. The results of the methanolic extracts of $P$. vulgaris yielded identical reading suggesting that there was no lethality observed hence, showing no effect whatsoever.

Regarding E.coli induced peritonitis, sampling of the tail blood at the end of the experiment was used to determine $E$. coli bacteria in all groups. Samples were serially diluted and plated on Nutrient agar in triplicates and counted the Colony at $24 \mathrm{hrs}$ after incubation at $30^{\circ} \mathrm{C}$. The mortality recorded in the sample consisting of $P$. vulgaris ME at $100 \mathrm{mg} / \mathrm{Kg}$ weight was reduced to $60 \%$ compared to $100 \%$ mortality in control suggesting that $\mathrm{ME}$ of $\mathrm{P}$ vulgaris showed a positive effect in reducing the mortality of $E$. coli induced peritonitis in laboratory-reared rats. Our study is in line with Azaz et al. found that hydro alcoholic extract $(250 \mathrm{mg} / \mathrm{Kg})$ of $P$. vulgaris showed the best inhibition in growth of $E$. coli in rats, and C.albicans growth was reduced at a dose of $400 \mathrm{mg} / \mathrm{kg}^{19}$.
Clearance Test is given in Table 2, Neutrophils Functions (Phagocytic Index) results are provided in Table 3. The neutrophil adhesion percentage was reduced in the sample of $100 \mathrm{mg} /$ $\mathrm{kg}$ which was 5.55 as compared to the control and standard which showed 6.10 and 7.13 percent of neutrophile adhesion. Phagocytosis by neutrophils is taken as the main defense system against microbial infections in peritonitis. Phagocytes play a crucial role in the prevention of sepsis by eliminating bacteria from the system. Therefore, effective clearing of bacteria is critical for host survival from infection.

\section{CONCLUSION}

P. vulgaris is widely distributed all across the world and grows wild; it constitutes a great repository of secondary metabolites with demonstrated therapeutic ability, and is available at relatively economical prices. In vitro results revealed that the methanolic extracts of Prunella vulgaris (MEPV) possess substantial antimicrobial activity both against bacteria and fungi. Under in vivo studies, it was confirmed that MEPV showed a positive effect in reducing the mortality of $E$. coli-induced peritonitis in laboratory-reared rats. Statistically showing almost similar action but in the case of ofloxacin, better results of clearance were observed at much lower concentration compared with the action shown by the MEPV. This investigation is unique in the sense that it evaluates the antimicrobial activity of the MEPV in both in vitro and in vivo and reports that the MEPV extracts restricted the growth of pathogenic bacteria to an acceptable extent not only in Petri plates but also in living animals, consequently, this report might constitute a pioneering study.

The results are although preliminary but support the existing scientific reports. The authors strongly recommend that since the plant extracts have the proven potential of antibiotic activity, an exhaustive study at a much greater scale may be carried out worldwide under the strict control of either reputed research laboratories or by the pharmaceutical industries to precisely evaluate and assess the extent of bioactivity contained in the crude extracts of at least some selected plants that may have demonstrated a track record of antimicrobial potential. 


\section{ACKNOWLEDGMENTS}

The authors are grateful to Dr. M.P. Dobhal and Prof. Arif Ali for critical assessment / review and English editing of the manuscript.

\section{CONFLICT OF INTEREST} conflict of interest.

The authors declare that there is no

\section{AUTHORS' CONTRIBUTION}

All authors listed have made a substantial, direct and intellectual contribution to the work, and approved it for publication.

\section{FUNDING}

None.

\section{DATA AVAILABILITY}

All datasets generated or analyzed during this study are included in the manuscript.

\section{ETHICS STATEMENT}

This study was carried out in accordance with the recommendations of Institutional Animal Ethics Committee (IAEC) of Pinnacle Biomedical Research Institute (PBRI), Bhopal (Reg. No. 1824/ $\mathrm{PO} / \mathrm{ERe} / \mathrm{S} / 15 / \mathrm{CPCSEA}$ ). The protocol was approved by the Institute Animal Care and Use Committee (NIH) under the protocol number PBRI/ IAEC/PN18032.

\section{REFERENCES}

1. Renisheya JJ, Malar T, Johnson M, Mary UM, Arthy A Antibacterial activities of ethanolic extracts of selected medicinal plants against human pathogens. Asian Pac J Trop Biomed. 2011;1(1):S76-S78. doi: 10.1016/S22211691(11)60128-7

2. Imtiaz B, Fozia, Waheed A, et al. Antimicrobial activity of Malva neglecta and Nasturtium microphyllum. Int J Res Ayurveda Pharm. 2012;3(6):808-810. doi: 10.7897/2277-4343.03624

3. Lamaison JL, Petitjean-Freyet C, Carnat A. Medicinal Lamiaceae with antioxidant properties, a potential source of rosmarinic acid. Pharm Acta Helv. 1991;66(7):185-188

4. Valdes-Sotomayor J, Cirugeda A, Bajo MA, et al. Increased severity of Escherichia coli peritonitis in peritoneal dialysis patients independent of changes in in vitro antimicrobial susceptibility testing. Perit Dial Int. 2003;23(5):450-455. doi: 10.1177/089686080302300508

5. Ingle KP, Deshmukh AG, Padole DA, Dudhare MS,
Moharil MP, Khelurkar VC. Phytochemicals: Extraction methods, identification, and detection of bioactive compounds from plant extracts. J Pharmacogn Phytochem. 2017;6:32-36.

6. Prior R, Wu X, Schaich K. Standardized methods for the determination of antioxidant capacity and phenolics in foods and dietary supplements. J Agric Food Chem. 2005;53(10):4290-4302. doi: 10.1021/jf0502698

7. Yeabyo S, Teka MZ, Gopalakrishnan VK, Kamalakararao K, Muthulingam M, Chaithanya KK. Immuno protective potential of Sida schimperiana chloroform root extract against $E$. coli 018: $\mathrm{K} 1$ induced peritonitis in albino Wistar rats. Res J Pharm Technol. 2021;14(4):22622269.doi: 10.52711/0974-360X.2021.00400

8. Teixeira-da-Cunha MG, Gomes RN, Roehrs N, et al. Bacterial clearance is improved in septic mice by platelet-activating factor-acetylhydrolase (PAF-AH) administration. PloS One. 2013;8(9):e74567. doi: 10.1371/journal.pone.0074567

9. Ghule BV, Yeole PG. In vitro and in vivo immunomodulatory activities of iridoids fraction from Barleriaprionitis Linn. J Ethnopharmacol. 2012;141(1):424-431. doi: 10.1016/j.jep.2012.03.005

10. Patel P, Asdaq SM. Immunomodulatory activity of methanolic fruit extract of Aeglemarmelos in experimental animals. Saudi Pharmaceutical Journal. 2010;18(3):161-165. doi: 10.1016/j.jsps.2010.05.006

11. Cloutier S, Wahl K, Baker C, Newberry RC. The social buffering effect of playful handling on responses to repeated intraperitoneal injections in laboratory rats. J Am Assoc Lab Anim Sci. 2014;53(2):168-173.

12. Parasuraman $S$, Raveendran R, Kesavan R. Blood sample collection in small laboratory animals. J Pharmacol Pharmacother. 2010;1(2):87-93. doi: 10.4103/0976-500X.72350

13. Daoud A, Malika D, Bakari S, et al. Assessment of polyphenol composition, antioxidant and antimicrobial properties of various extracts of Date Palm Pollen (DPP) from two Tunisian cultivars. Arabian Journal of Chemistry. 2019;12(8):3075-3086. doi: 10.1016/j. arabjc.2015.07.014

14. Maurya S, Singh D. Quantitative analysis of total phenolic content in Adhatodavasica Nees extracts. Int J Pharmtech Res. 2010;2(4):2403-2406.

15. Murray PR, Baron EJ, Pfaller MA, Tenover FC, Yolke $\mathrm{RH}$. Manual of Clinical Microbiology, $6^{\text {th }}$ edition. ASM, Washington, DC. 1995.

16. Nascimento GGF, Locatelli J, Freitas PC, Silva GL. Antibacterial activity of plant extracts and phytochemicals on antibiotic-resistant bacteria. Braz J Microbiol. 2000;31(4):247-256. doi: 10.1590/S151783822000000400003

17. Khadagwanshi D, Trivedi S, Patel P, Jha M. Effect of Phaseolus vulgaris on E. coli induced peritonitis and bacteremia in mice. J Drug Delivery and Therapeutics. 2019;9(4-s):310-314. doi: 10.22270/jddt.v9i4-s.3323

18. Mahboubi M, Mahboubi A, Kazempouur N. The antimicrobial activity of Prunella vulgaris extracts. Herba Polonica. 2015;61(1):31-38. doi: 10.1515/hepo2015-0008 
Patel et al. | J Pure Appl Microbiol | 15(3):1429-1441 | September 2021 | https://doi.org/10.22207/JPAM.15.3.35

19. NayaA, Khan MA, Sharma P, Mishra RM. Phytochemical screening, antioxidant and antimicrobial activities of Prunella vulgaris for oral thrush. Journal of Drug Delivery \&Therapeutics. 2018;8(5-s): 251-258. doi: 10.22270/jddt.v8i5-s.1966
20

Dewanto V, Wu X, Adom KK, Liu RH. Thermal processing enhances the nutritional value of tomatoes by increasing total antioxidant activity. Journal of Agricultural and Food Chemistry. 2002;50(10):30103014. doi: 10.1021/jf0115589 